\title{
Localized and systemic bacterial infections in necrotizing pancreatitis submitted to surgical necrosectomy or percutaneous drainage of necrotic secretions
}

Bruno Cacopardo ${ }^{1 *}$, Marilia Rita Pinzone ${ }^{1}$, Salvatore Berretta², Rossella Fisichella², Maria Di Vita², Guido Zanghì ${ }^{2}$ Alessandro Cappellani ${ }^{2}$, Giuseppe Nunnari ${ }^{1}$, Antonio Zanghi ${ }^{2}$

From 26th National Congress of the Italian Society of Geriatric Surgery

Naples, Italy. 19-22 June 2013

\begin{abstract}
Background: Infectious complications are observed in 40-70\% of all patients with severe acute pancreatitis. Infections are associated with a significant increase in mortality rates.

Methods: We evaluated the prevalence and characteristics of pancreatic and systemic infections in 46 patients with necrotizing pancreatitis submitted to surgical procedures during their hospital stay as well as the impact of such infectious complications on patient clinical outcome. Samples for microbiological cultures were taken at hospital admission from blood and bile and 2 days after invasive procedure from blood, drainage fluid, bile and necrotic tissues.
\end{abstract}

Results: 74\% patients with necrotizing pancreatitis had a localized or systemic infection. At admission, 15\% of subjects had positive blood cultures whereas $13 \%$ had evidence of bacterial growth from bile cultures. Two days after the invasive procedures for removal of necrotic materials and fluids, blood cultures became positive in $30 \%$ of patients in spite of antibiotic prophylaxis and bile cultures resulted positive in $22 \%$ of cases. Furthermore, bacterial growth from drainage fluids was found in 30\% and from homogenized necrotic material in $44 \%$ of cases. As refers to bacterial isolates, all patients had a monomicrobial infection. Carbapenems were the drugs with the best sensitivity profile.

Mortality rate was significantly $(p<0.05)$ higher among patients with infection $(17 \%)$ than subjects without infection (8\%). Within the infected group, those subjects with evidence of systemic infection (positive blood cultures) developed more complications and demonstrated a higher $(p<0.05)$ mortality rate $(28 \%)$ than those who had only a localized infection (10\%).

Conclusions: Infectious complications significantly increase mortality in patients with necrotizing pancreatitis. In addition, subjects with systemic infections developed more complications and demonstrated a higher mortality rate in comparison with those having a localized infection. In our study, the sensitivity pattern of the isolated microorganisms suggests to consider carbapenems as the best option for empirical treatment in patients with necrotizing pancreatitis who develop a clear-cut evidence of systemic or localized bacterial infection.

\footnotetext{
* Correspondence: cacopardobruno@inwind.it

'Department of Clinical and Molecular Biomedicine, Division of Infectious

Diseases, University of Catania, 95125 Catania, Italy

Full list of author information is available at the end of the article
} 


\section{Background}

Infectious complications are observed in $40-70 \%$ of all patients with severe acute pancreatitis [1-3]. Mortality usually peaks within the first 7-10 days as a result of infectious complications, either limited to pancreatic necrotic areas or spread in the bloodstream [4,5].

Sterile pancreatic necrosis has a mortality rate of $20 \%$, whereas it increases to more than $50 \%$ in the case of infected necrosis [6]. There is evidence that the involved bacteria originate from the gastrointestinal tract by transepithelial traslocation [7].

These patients are often given prophylactic antibiotics, although the use of this strategy may result in the development of an infection with resistant bacteria.

We conducted a study aimed at evaluating the prevalence and characteristics of pancreatic and systemic infections in patients with necrotizing pancreatitis submitted to surgical procedures during their hospital stay. We also evaluated the impact of such infectious complications on patient clinical outcome.

\section{Patients and methods}

46 patients affected with acute necrotizing pancreatitis were consecutively enrolled among those admitted over a five-year period (2006-2011) at the Department of Surgery, University Hospital of Catania. The diagnosis of acute pancreatitis was based on clinical features, elevated serum amylase and/or lipase levels (more than 4fold the upper reference limit) and evidence of pancreatic abnormalities on contrast-enhanced computed tomography (CECT) of the abdomen. The most common etiologies were gallstones (21 cases), alcohol (14 cases) and pancreotoxic drugs (8 cases), whereas 3 cases originated from abdominal traumas. The CT Severity Index [8] was 10 in 22 cases, 9 in 14 patients and 8 in the remainder 10 patients. All patients were closely monitored with adequate amounts of intravenous fluids and pain management. Supportive measures such as enteral nutrition and antibiotic prophylaxis were adopted in all cases. All 46 cases were managed invasively: 16 cases were treated by open surgical removal of necrotic areas, 15 cases underwent percutaneous catheter drainage of necrotic secretions, 15 cases received minimally invasive retroperitoneal necrosectomy. Seven of 46 patients (15\%) died within 3 weeks from the onset of the disease.

Samples for microbiological cultures were taken at hospital admission from blood and bile and 2 days after invasive procedure from blood, drainage fluid, bile and necrotic tissues. Necrotic tissue samples from patients undergoing necrosectomy were homogenized immediately before culture.

The protocol for the study was approved by the Ethical Committee of our institution and written informed consent was obtained from all patients. The study protocol conformed to the ethical guidelines of the Declaration of Helsinki.

Statistical analysis was carried out using the statistical software package SPSS version 17.0 (SPSS, Chicago, Illinois, USA). A two-tailed P value of less than 0.05 was considered significant. All quantitative variables were expressed as mean \pm standard deviation (SD). The chisquare test and the Fisher's exact test were adopted for statistical comparisons.

\section{Results}

In our study population, mean age was $63 \pm 17$ years, 24 (52\%) were males. Comprehensively, in 34 of 46 (74\%) patients with necrotizing pancreatitis cultures demonstrated the presence of a localized or systemic infection.

In more detail, at hospital admission 7 of 46 patients (15\%) already showed positive blood cultures whereas 6 (13\%) had evidence of bacterial growth from bile cultures. Two days after the invasive procedures for removal of necrotic materials and fluids, blood cultures became positive in 14 of 46 patients (30\%) in spite of antibiotic prophylaxis and bile cultures resulted positive in 10 patients $(22 \%)$. Furthermore, bacterial growth from drainage fluids was found in 14 patients $(30 \%)$ and from homogenized necrotic material in 20 (44\%) cases. All those patients with positive bile or blood cultures also had infection of necrotic material.

As refers to bacterial isolates, all patients had a monomicrobial infection. Table 1 shows the cultured microorganisms with reference to the source sites. Table 2 shows the antibiotic resistance rates of the isolated strains.

As refers to the clinical outcome, mortality rate was significantly $(\mathrm{p}<0.05)$ higher among patients with infection $(\mathrm{N}=34)$ than subjects without infection $(\mathrm{N}=12): 6(17 \%)$

Table 1 Number of isolated strains and site of isolation among 46 patients with necrotizing pancreatitis

\begin{tabular}{|c|c|c|c|c|}
\hline & \multicolumn{4}{|c|}{ N. isolated strains } \\
\hline & Blood & Bile & Drainage & $\begin{array}{l}\text { Necrotic } \\
\text { material }\end{array}$ \\
\hline \multicolumn{5}{|l|}{ Gram-negative bacteria } \\
\hline Escherichia coli & 4 & 4 & 7 & 10 \\
\hline Pseudomonas aeruginosa & 2 & 2 & 1 & 3 \\
\hline Klebsiella pneumoniae & 2 & 2 & 1 & - \\
\hline Proteus mirabilis & 1 & 2 & 1 & 1 \\
\hline Acinetobacter baumannii & - & - & - & 1 \\
\hline \multicolumn{5}{|l|}{ Gram-positive bacteria } \\
\hline $\begin{array}{l}\text { Coagulase negative } \\
\text { Staphylococci (CNS) } \\
\end{array}$ & 6 & 2 & 1 & 1 \\
\hline $\begin{array}{l}\text { Methicillin-resistant } \\
\text { Staphylococcus aureus (MRSA) }\end{array}$ & 1 & - & 1 & 2 \\
\hline Enterococcus faecium & 3 & 2 & 1 & 1 \\
\hline Enterococcus faecalis & 2 & 2 & 1 & 1 \\
\hline
\end{tabular}


Table 2 Antibiotic resistance rates (\%) of all the isolated bacteria among 46 patients with necrotizing pancreatitis

\begin{tabular}{|c|c|c|c|c|c|c|c|c|}
\hline & E. coli & P. aeruginosa & K. pneumoniae & P. mirabilis & A. baumannii & E. faecium/faecalis & CNS & MRSA \\
\hline Amoxi/Clavulanate & 22 & 48 & 60 & 32 & 100 & 100 & 50 & 100 \\
\hline Amikacin & 10 & 20 & 12 & 18 & 88 & 44 & 58 & 100 \\
\hline Ampi/Sulbactam & 22 & 48 & 60 & 36 & 100 & 40 & 68 & 100 \\
\hline Cefotaxime & 54 & 68 & 72 & 44 & 100 & 42 & 36 & 92 \\
\hline Ceftazidime & 32 & 38 & 38 & 20 & 88 & 100 & 78 & 100 \\
\hline Ceftriaxone & 40 & 60 & 44 & 42 & 100 & 100 & 56 & 92 \\
\hline Ciprofloxacin & 24 & 82 & 62 & 26 & 92 & 42 & 22 & 78 \\
\hline Imipenem & 2 & 12 & 8 & 0 & 24 & - & - & - \\
\hline Levofloxacin & 24 & 82 & 52 & 16 & 100 & 40 & 20 & 56 \\
\hline Meropenem & 0 & 6 & 2 & 0 & 16 & - & - & - \\
\hline Piperacillin/Tazobactam & 22 & 48 & 26 & 16 & 58 & 90 & 40 & 100 \\
\hline Linezolid & - & - & - & - & - & 2 & 0 & 2 \\
\hline Vancomycin & - & - & - & - & - & 2 & 0 & 2 \\
\hline Rifampicin & 80 & 100 & 68 & 88 & 2 & 2 & 0 & 68 \\
\hline Cotrimoxazole & 32 & 100 & 40 & 38 & 100 & 100 & 0 & 50 \\
\hline
\end{tabular}

MRSA: Methicillin-resistant Staphylococcus aureus; CNS: Coagulase negative Staphylococci

vs. $1(8 \%)$, respectively. Within the infected group, those 14 subjects with evidence of systemic infection (positive blood cultures) developed more complications (Table 3) and demonstrated a higher $(\mathrm{p}<0.05)$ mortality rate in comparison with those who had only a localized infection (limited to necrotic material, bile or drainage fluids): 4 (28\%) vs. $2(10 \%)$, respectively.

\section{Discussion}

In the present study, we examined pancreatic and systemic infections in patients with necrotizing pancreatitis. In keeping with previous studies, the prevalence of infections in this setting usually correlates with the extent of pancreatic necrosis $[9,10]$.

In our experience, comprehensive rate of infection was $74 \%$, with an overall prevalence of bloodstream infections of $30 \%$ and a rate of localized infections within pancreatic necrotic areas exceeding $40 \%$. Noor et al. [11] observed pancreatic infections in $37.3 \%$ of patients

Table 3 Complications developed among patients with evidence of systemic or localized infection

\begin{tabular}{lll}
\hline & $\begin{array}{l}\text { Bloodstream } \\
\text { infection } \\
\mathbf{N}=\mathbf{1 4}\end{array}$ & $\begin{array}{l}\text { Infection of necrotic } \\
\text { tissue/bile/drainage fluids } \\
\mathbf{N = 2 0}\end{array}$ \\
\hline Pleural effusion & $4(28 \%)$ & $2(10 \%)$ \\
\hline Pericardial effusion & $3(21 \%)$ & $1(5 \%)$ \\
\hline Pneumonia & $3(21 \%)$ & 0 \\
\hline Cerebral abscess & $1(7 \%)$ & 0 \\
\hline Septic shock & $3(21 \%)$ & $1(5 \%)$ \\
\hline DIC & $1(7 \%)$ & 0 \\
\hline
\end{tabular}

DIC: Disseminated Intravascular Coagulation and extrapancreatic infections in $62.7 \%$ of patients with severe acute pancreatitis.

In a study by Garg et al. [12], extrapancreatic bacterial infections were found in $31.7 \%$ of 63 patients. Bourgaux et al. [13] reported extrapancreatic infections in $25 \%$ of their patients. The most common sites of infection were the peritoneal fluid (26.8\%) and blood (24.4\%). Finally, in a recent study by Besselink et al. [14], bacteremia was reported only in $13.4 \%$ of the enrolled cases.

Similarly to our data, in patients with pancreatic infections monomicrobial infections were reported to be more common than polymicrobial ones [11].

The most common mechanism for early infection in acute necrotizing pancreatitis involves bacterial translocation from the gut. This could explain the high frequency of pancreatic and systemic infections by Escherichia coli we found in our study. Recently, Su et al. [15] described Escherichia coli to be the most common microbe responsible for infection in patients with severe acute pancreatitis.

Infections with Gram-positive organisms could occur later due to nosocomial bloodstream spread [11]. Actually, a progressive shift from Gram-negative to Grampositive organisms might occur either associated to the increasing length of hospital stay or related to the administration of prophylactic antibiotics mainly targeting Gram-negative bacteria [14].

Previous studies emphasized the role of pancreatic infections as unfavorable predictors of patient clinical outcome. Noor et al. [11] reported mortality to be significantly higher in patients with pancreatic infections. Also, in the study by Besselink et al. [14] patients with infected pancreatic necrotic areas had a higher mortality 
rate. Differently from them, our study showed that bacteremic infections throughout the course of necrotizing pancreatitis worsened the outcome of the disease much more than localized infections either in terms of development of complications or in terms of crude mortality rate. Actually, in the study by Besselink et al. [14] the highest mortality rates were found in those cases with concomitant pancreatic and bacteremic infection.

The results of the sensitivity pattern of the isolated microorganisms suggest that carbapenems should be evaluated for empirical treatment in those patients with necrotizing pancreatitis who develop a clear-cut evidence of systemic or localized bacterial infection.

\section{Competing interests}

The authors declare that they have no competing interests.

\section{Authors' contributions}

$\mathrm{BC}$ : conception and design, interpretation of data, statistical analysis, critical revision, given final approval of the version to be published. MRP: acquisition of data, drafting the manuscript, statistical analysis, given final approval of the version to be published. SB: acquisition of data, given final approval of the version to be published. RF: acquisition of data, given final approval of the version to be published. MDV: acquisition of data, given final approval of the version to be published. GZ: acquisition of data, given final approval of the version to be published. AC: acquisition of data, given final approval of the version to be published. GN: acquisition of data, drafting the manuscript, given final approval of the version to be published. AZ: interpretation of data, critical revision, given final approval of the version to be published.

\section{Authors' information}

BC: Associate Professor of Infectious Diseases at University of Catania MRP: Resident in Infectious Diseases at University of Catania

SB: Full Professor of Surgery at University of Catania

RF: Resident in Surgery at University of Catania

MDV: Assistant Professor of Surgery at University of Catania

GZ: Associate Professor of Surgery at University of Catania

AC: Associate Professor of Surgery at University of Catania

GN: Assistant Professor of Infectious Diseases at University of Catania

AZ: Associate Professor of Surgery at University of Catania

\section{Declarations}

Publication of this article was funded by the Department of Clinical and Molecular Biomedicine, University of Catania.

This article has been published as part of BMC Surgery Volume 13 Supplement 2, 2013: Proceedings from the 26th National Congress of the Italian Society of Geriatric Surgery. The full contents of the supplement are available online at http://www.biomedcentral.com/bmcsurg/supplements/13/S2

\section{Authors' details}

'Department of Clinical and Molecular Biomedicine, Division of Infectious Diseases, University of Catania, 95125 Catania, Italy. ${ }^{2}$ Department of Surgery, General Surgery Unit, University of Catania, 95100 Catania, Italy.

Published: 8 October 2013

\section{References}

1. Gloor B, Muller CA, Worni M, Stahel PF, Redaelli C, Uhl W, Buchler MW: Pancreatic infection in severe pancreatitis: the role of fungus and multiresistant organisms. Arch Surg 2001, 136(5):592-596.

2. Beger $H G$, Bittner R, Block S, Buchler M: Bacterial contamination of pancreatic necrosis: a prospective clinical study. Gastroenterology 1986, 91(2):433-438.

3. Schmid SW, Uhl W, Friess $H$, Malfertheiner P, Buchler MW: The role of infection in acute pancreatitis. Gut 1999, 45(2):311-316.
4. Isenmann R, Rau B, Beger HG: Bacterial infection and extent of necrosis are determinants of organ failure in patients with acute necrotizing pancreatitis. Br J Surg 1999, 86(8):1020-1024.

5. Gerzof SG, Banks PA, Robbins AH, Johnson WC, Spechler SJ, Wetzner SM, Snider JM, Langevin RE, Jay ME: Early diagnosis of pancreatic infection by computed tomography guided aspiration. Gastroenterology 1987, 93(6):1315-1320

6. De Beaux AC, Palmer KR, Carter DC: Factors influencing morbidity and mortality in acute pancreatitis: an analysis of 279 cases. Gut 1995, 37(1):121-126.

7. Capurso G, Zerboni G, Signoretti M, Valente R, Stigliano S, Piciucchi M, Delle Fave G: Role of the gut barrier in acute pancreatitis. J Clin Gastroenterol 2012, 46(suppl):S46-51.

8. Mir MA, Bali BS, Mir RA, Wani H: Assessment of the severity of acute pancreatitis by contrast-enhanced computerized tomography in 350 patients. Ulus Travma Acil Cerrahi Derg 2013, 19(2):103-108.

9. Babu RY, Gupta R, Kang M, Bhasin DK, Rana SS, Singh R: Predictors of surgery in patients with severe acute pancreatitis managed by the stepup approach. Ann Surg 2013, 257(4):737-750.

10. Khan GM, Li JJ, Tenner S: Association of extent and infection of pancreatic necrosis with organ failure and death in acute necrotizing pancreatitis. Clin Gastroenterol Hepatol 2005, 3(8):829.

11. Noor MT, Radhakrishna Y, Kochhar R, Ray P, Wig JD, Sinha SK, Singh K: Bacteriology of infection in severe acute pancreatitis. J Pancreas 2011, 12(1):19-25.

12. Garg PK, Khanna S, Bohidar NP, Kapil A, Tandon RK: Incidence, spectrum and antibiotic sensitivity pattern of bacterial infections among patients with acute pancreatitis. J Gastroenterol Hepatol 2001, 16(9):1055-1059.

13. Bourgaux JF, Defez C, Muller L, Vivancos J, Prudhomme M, Navarro F, Pouderoux P, Sotto A: Infectious complications, prognostic factors and assessment of antiinfectious management of 212 consecutive patients with acute pancreatitis. Gastroenterol Clin Biol 2007, 31(4):431-435.

14. Besselink MG, van Santvoort HC, Boermeester MA, Nieuwenhuijs VB, van Goor H, Dejong CH, Schaapherder AF, Gooszen HG, Dutch Acute Pancreatitis Study Group: Timing and impact of infections in acute pancreatitis. Br J Surg 2009, 96(3):267-273.

15. Su MS, Lin M, Zhao Q, Liu Z, He L, Jia N: Clinical study of distribution and drug resistance of pathogens in patients with severe acute pancreatitis. Chin Med J 2012, 125(10):1772-1776.

doi:10.1186/1471-2482-13-S2-S50

Cite this article as: Cacopardo et al.: Localized and systemic bacterial infections in necrotizing pancreatitis submitted to surgical necrosectomy or percutaneous drainage of necrotic secretions. BMC Surgery 2013 13(Suppl 2):S50.

\section{Submit your next manuscript to BioMed Central and take full advantage of:}

- Convenient online submission

- Thorough peer review

- No space constraints or color figure charges

- Immediate publication on acceptance

- Inclusion in PubMed, CAS, Scopus and Google Scholar

- Research which is freely available for redistribution
C Biomed Central 